\title{
A Matemática Solidária no estudo do Tratamento da Informação
}

Gabriele Silva Carneiro Batista

\section{Resumo}

Esta atividade foi destinada às turmas do $8^{\circ}$ e $9^{\circ}$ ano do ensino fundamental, na escola estadual da Polícia Militar Eraldo Tinoco em Vitória da Conquista - BA. O objetivo foi investigar a viabilidade do desenvolvimento de conteúdos procedimentais, atitudinais e conceituais matemáticos, envolvendo coleta e doações de agasalhos em comemoração aos 10 anos do Sistema Único de Assistência Social (SUAS). O projeto "A matemática solidária no estudo do Tratamento da informação" envolveu métodos multidisciplinares sobre temas que envolviam cidadania, normas técnicas textuais, cálculos matemáticos, investigação e construções e análises de tabelas e gráficos. Tivemos um tutorial, a $1^{\circ}$ etapa foi à arrecadação das roupas, para construção da tabela e operações solicitadas. Após os cálculos, iniciamos a pesquisa, os aprendizes investigaram o conteúdo matemático, construindo o seu conhecimento com as descobertas. Após a exploração do assunto, estrearíamos a construção gráfica fazendo comparações com os dados coletados. O trabalho escrito seguiu alguns protocolos da Associação Brasileira de Normas Técnicas (ABNT), a qual foi estabelecida na aula de matemática durante a explicação do tutorial. As roupas foram destinadas ao Centro Pop Adultos e Adolescente em Vitória da Conquista, e na culminância do projeto, tivemos a participação de quatro representantes da associação popular, para falar sobre as ações desenvolvidas na instituição e abrimos uma discussão com os estudantes sobre a temática.

Palavras-chave: Tratamento da informação; Ensino de Matemática; Solidariedade; Aprendizagem. 


\section{Justificativa}

Considerando que o direito à cidadania está, diretamente, relacionado com as condições sociais, não é possível conceber o ensino e aprendizagem de matemática desvinculados da realidade social em que vivemos. Fato este que exige do ato de ensinar uma ação reflexiva e política. Pessoa (2002) considera que a partir do conhecimento matemático, seja possível o estudante criticar questões sociais, políticas, econômicas e históricas.

Ao propor uma educação comprometida com a cidadania os Parâmetros Curriculares Nacionais (PCNs) elegeram baseados no texto constitucional, princípios segundo os quais orientam a educação escolar na busca da dignidade da pessoa humana, igualdade de direitos, participação e co-responsabilidade pela vida social. Estas diretrizes têm exigido a necessidade de elaborar propostas que de fato permitam articular os conteúdos estruturantes da matemática com a construção da cidadania (PASSOS, 1999).

Trata-se do reconhecimento de que a matemática está presente na vida cotidiana de todo cidadão, por vezes de forma explícita e por vezes de forma sutil. Sendo assim, entendese que um projeto educativo comprometido com a formação integral do cidadão deve se inspirar no que a Constituição preconiza e estabelecer mecanismos de efetivação para os mesmos. É nessa perspectiva que o Projeto "Matemática Solidária no Ensino do Tratamento da Informação" foi realizado, buscando estabelecer um contexto de ação e interação onde a participação, criação de regras de convivência, possibilita o exercício de direitos e deveres, preparando os envolvidos para o exercício da cidadania.

É neste contexto que o atual projeto foi desenvolvido junto aos estudantes do $8^{\circ}$ e $9^{\circ}$ ano da escola estadual da Polícia Militar Eraldo Tinoco situado na zona urbana do município de Vitoria da Conquista/BA, a partir das aulas de matemática, buscando construir conhecimentos conceituais matemáticos aliados a conhecimentos procedimentais e atitudinais que contribuam para a formação cidadã da comunidade onde a escola se insere.

Fazer uma reflexão sobre a origem das ideias matemáticas e o seu surgimento pode ser um ponto de partida para este desafio. Segundo Ubiratan D’Ambrosio (2005): “A espécie cria teorias e práticas que resolvem a questão existencial. Essas teorias e práticas são as bases de elaboração de conhecimento e decisões de comportamento, a partir de representações da realidade". Ou seja, somos levados a deduzir que o conhecimento não é fruto de um simples reflexo da realidade, mas é a integração das características objetivas de uma situação ou de um fato, com as experiências anteriores do grupo e seu sistema de atitudes, normas e valores.

Isto nos remete segundo Garcia (2006), a pensar que o conhecimento matemático é uma representação social, por mais objetivas que possam parecer suas leis expressas num conjunto de fórmulas. $\mathrm{E}$, que o conhecimento matemático é continuamente criado e recriado à medida que as pessoas atuam e refletem sobre o mundo. Logo, defendemos que o ISSN 2526-2882 
conhecimento é um produto emergente da ação e da interação da consciência humana e da realidade, interagindo a todo momento para recriar a percepção e descrição da realidade.

Para exercer a cidadania é importante saber calcular, medir, raciocinar, argumentar, tratar informações estatisticamente. Para isso todos devem ter acesso aos conhecimentos e instrumentos matemáticos presentes em qualquer codificação da realidade, como uma condição necessária para participarem e interferirem na sociedade em que vivem. "O educador democrático não pode negar-se o dever de, na sua prática docente, reforçar a capacidade crítica do educando, sua curiosidade, sua insubmissão". (FREIRE, 2007, p.26)

É importante que a educação matemática prepare seus aprendizes para a criticidade, para a indignação, para a cidadania e não para a alienação e para a exclusão. No entanto, para trilharmos esse caminho é necessário refletirmos sobre novas práticas pedagógicas para o ensino de matemática, a partir de tendências pedagógicas que referendam os marcos teóricos destacados, possibilitando a relação entre matemática e cidadania.

\section{Objetivos}

A finalidade desse projeto foi investigar a viabilidade do desenvolvimento de conteúdos procedimentais, atitudinais e conceituais matemáticos, a partir do Projeto Matemática Solidária no Estudo do Tratamento da Informação, como forma de estabelecer relações entre a matemática e necessidades que emergem do cotidiano da comunidade. Alinhado a essas ideias o desenvolvimento do projeto buscou oportunizar espaços de interação e participação, onde, cada aprendiz teve que seguir as regras criadas e solucionar em conjunto as dificuldades e problemas que eventualmente surgiram durante o processo do estudo, da organização e da construção.

Deste modo, tivemos a pretensão de relacionar a matemática com os diversos fatores sociais, mostrando que a escola pode se constituir em local de apoio para o desenvolvimento de atividades e ações que contemplem não só o trabalho com conteúdos conceituais, relacionados ao currículo estabelecido formalmente, mas também, oportunizar novos conhecimentos que podem estimular a participação cidadã e contribuir para o processo de ensino aprendizagem.

Outro fator importante foi à possibilidade de levar o estudante a refletir sobre as questões sociais possibilitando um ambiente onde mudanças possam ocorrer, como um reflexo do conhecimento construído. Para Ferreira (2003), esse convívio pode gerar mudanças entre os participantes do grupo, promovendo o cuidado uns com os outros, o qual poderá se estender para outras estruturas da sociedade rompendo com relações autoritárias, dominadoras, impositivas que podem gerar a violência nas escolas. 
Sem falar nos benefícios para o aprendizado da matemática, pois, a todo o momento o aluno é colocado a uma situação problema, desenvolvendo o raciocínio lógico e a capacidade de análise/tabulação. Neste sentido, colocarmos os participantes em condições de sujeito de seu refletir e de seu fazer, onde os mesmos sejam construtores e formadores de suas ideologias, deixando para trás tarefas isoladas e rotineiras, procurando inovar de forma positiva o processo de ensino e aprendizagem.

\section{Métodos/Procedimentos}

O ambiente educacional foi o espaço escolhido para o desenvolvimento da proposta, ocorreu na escola estadual da Polícia Militar Eraldo Tinoco situado na zona urbana do município de Vitoria da Conquista/BA. Os sujeitos envolvidos no estudo, além do professor pesquisador, foram estudantes do $8^{\circ}$ e $9^{\circ}$ ano do ensino fundamental e toda a proposta foi realizada no período da segunda unidade no ano letivo de 2015.

Passamos por cinco etapas até chegarmos ao momento da culminância e percepção dos efeitos sobre a ideia inovadora. Deste modo, o projeto "matemática solidária no ensino do Tratamento da Informação" foi estruturado e constituído da seguinte maneira:

1etapa: Entrega e explicação em sala de aula do Tutorial (material que possui todas as informações necessárias para o trabalho), a partir desse momento os participantes iniciariam a arrecadação das roupas de frio.

2ºtapa: Construção da tabela seguindo modelo apresentado no Tutorial, destacando cada peça de roupa e associando a um valor numérico que foi estabelecido pelo professor pesquisador no momento da aula. Ainda nessa etapa foi solicitado alguns cálculos com as roupas que foram arrecadadas, fazendo-se separações por peças e agrupando para futuras análises.

$3^{\circ}$ etapa: Após os cálculos, estrearíamos as construções gráficas, fazendo comparações com os dados coletados. Utilizamos o programa Excel para a construção dos gráficos, já que as turmas já haviam estudado programa nas aulas de Tecnologia Educacional.

$4^{\circ}$ etapa: Nessa etapa focamos a pesquisa, em que, os aprendizes investigaram sobre o conteúdo matemático Tratamento da Informação, apresentando durante as aulas as suas descobertas, criando um espaço de socialização, discussão e reflexão com a turma. O trabalho escrito seguiu alguns protocolos da Associação Brasileira de Normas Técnicas (ABNT), a qual foi estabelecida no período de explicação do tutorial.

$5^{\circ}$ etapa: Esse momento foi o mais esperado, a entrega das roupas de frio, os materiais de doação foram destinados ao Centro Pop Adultos e Adolescente em Vitória da Conquista, sendo que o momento caracterizou como a culminância do projeto, onde tivemos a palestra do Diretor da instituição e também, quatro ex-moradores de rua, que graças a ação social do 
grupo, conseguiram resgatar a sua dignidade, apresentando alguns relatos chocantes sobre suas vidas. Assim abrimos para uma discussão com os estudantes sobre a temática. Para finalizar essa etapa, utilizamos outro dia de aula para uma reflexão sobre os conhecimentos adquiridos, através da resolução de atividades contendo questões de conteúdos conceituais matemáticos, de conhecimentos pra práticas solidarias, de conteúdos atitudinais e questões avaliativas do trabalho realizado.

Já o processo de avaliação acompanhou uma reflexão do realizado, dos acertos e desacertos, a percepção e expectativas dos participantes sobre as atividades e resultados obtidos durante todo o processo. Neste sentido, a avaliação tornou-se uma constante para que se pudessem compreender as contradições no desenrolar das atividades. Apresentamos, então, o Tutorial da atividade, conforme está sendo abordada no Quadro um, e que foi delineada da seguinte maneira:

Quadro 1: Tutorial - Trabalho de Matemática

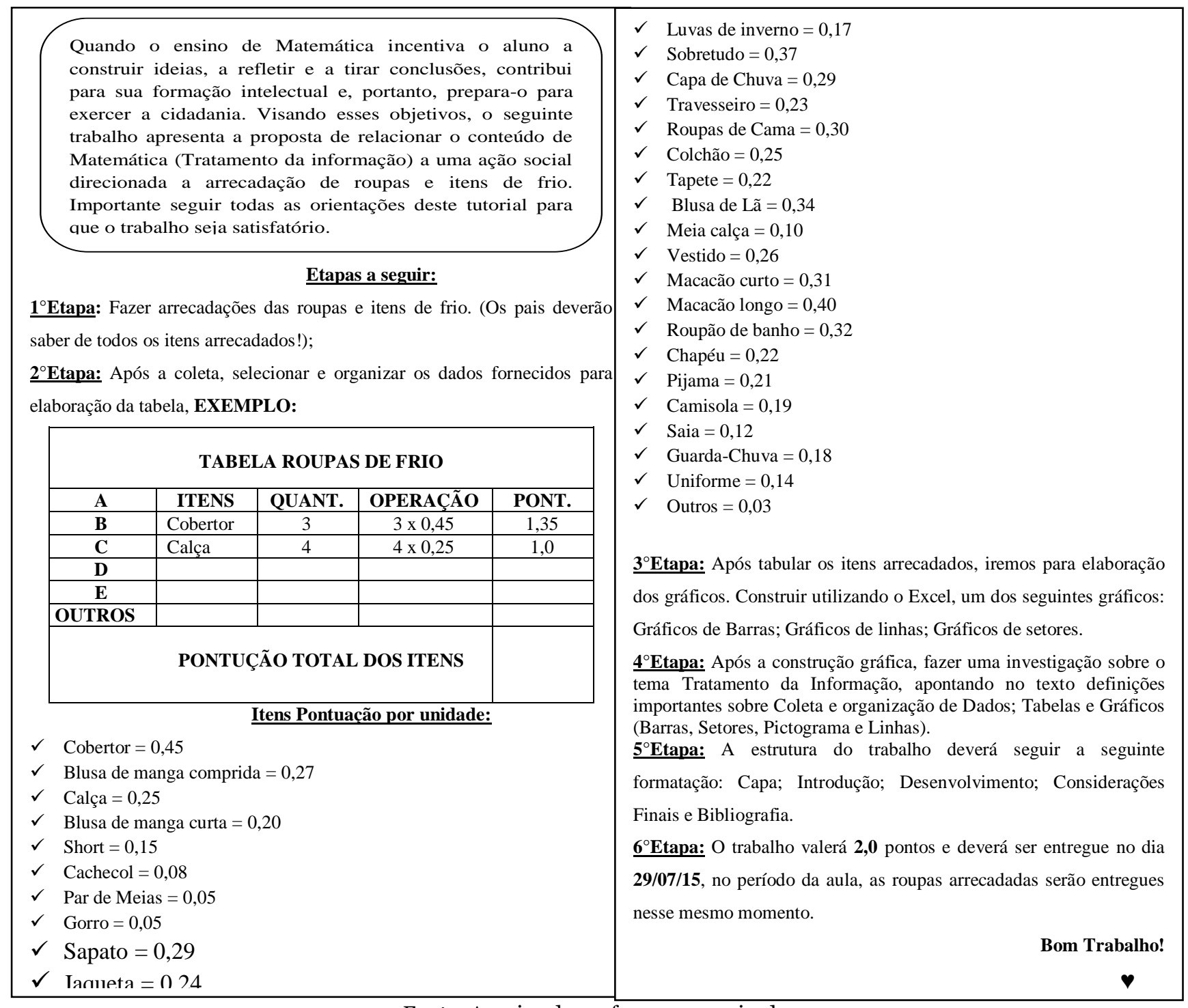

Fonte: Arquivo da professora pesquisadora

ISSN 2526-2882 


\section{Reflexões /análise da prática}

O grupo de estudantes do projeto Matemática Solidária no Estudo do Tratamento da Informação envolveram-se no processo, colocando-se num espaço de trabalho coletivo, interativo, que pode ser potencializado com mediações pedagógicas favoráveis a partir do ensinar e aprender mútuo. Assim os participantes tiveram que se relacionar com todos os envolvidos de maneira afetiva, dialógica para atender necessidades próprias e dos outros.

Ao realizar uma análise crítica sobre a atual prática e as manifestações dos estudantes participantes do projeto, foi possível perceber que cada um apresentou maneiras próprias de se expressar, organizar e agir. Um aspecto importante a ressaltar refere-se à postura autônoma e responsável com que se conduziram ao longo do trabalho. Além disso, foi possível perceber que, entre os participantes do grupo, existiu um relacionamento solidário e comprometido com a totalidade.

No que se refere aos conteúdos procedimentais e conceituais matemáticos envolvidos relacionados a operações com números naturais, comparação de dados, construções e analises de tabelas e gráficos, organização de espaços e a resolução de problemas foram fortemente trabalhados ao longo do projeto, sendo que os estudantes apresentaram desempenho satisfatório tanto em atividades como em avaliações.

Considera-se que no período de realização e no âmbito do projeto os estudantes envolveram-se com a proposta, vivenciaram a possibilidade de trocas solidárias, discutiram e refletiram sobre a possibilidade da mesma fazer parte da rotina escolar, apresentando ideias e planos para a realização do projeto no ano seguinte, podendo ter a participação de todas as disciplinas do currículo escolar, ampliando para um projeto maior e até mesmo estruturante.

A separação e contagem das roupas foi um momento muito gratificante aos idealizadores e participantes do projeto, pois conseguimos um total de 5200 peças, incluindo roupas de cama, cobertores, edredons e mantas para bebês. Diante de todas essas conquistas, não poderíamos deixar de mencionar e parabenizar o Sistema Único de Assistência Social (SUAS) pelos seus 10 anos, o qual contribuiu positivamente para a construção desse projeto e que vem sempre apoiando e protegendo a população, com recursos e profissionais qualificados para garantir direitos, enfrentar a pobreza e proteger as pessoas mais vulneráveis.

O trabalho colaborou para desenvolver o espírito crítico e a capacidade de análise, dando condições para exercer a cidadania e tomar decisões em um mundo cada vez mais dinâmico. Portanto, a proposta desenvolvida mostrou limites para avançar nessa temática, mas também os avanços nos processos de conscientização dos alunos.

Essa experiência permitiu interpretar, refletir e criar processos de ensino inovadores, numa prática produtiva e dinâmica, e de reinventar o ato de educar. ISSN 2526-2882

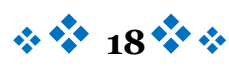


Corroborando com Morin (2008), podemos utilizar várias alternativas para tornar a aprendizagem mais expressiva e as relações de socialização na sala de aula bem mais interativa, podendo afirma que a atual prática contribuiu para o amadurecimento intelectual e liberdade profissional.

Como o projeto foi uma proposta prática, as dificuldades para a sua realização foram pequenas, uma delas, foi o laboratório de informática que no momento estava em reforma, impossibilitando os alunos de realizarem as atividades no espaço, tendo que construir a tabela e os gráficos em diferentes ambientes. Outro problema foi encontrar espaços para guardar as roupas já que conseguimos uma quantidade considerável de roupas e agasalhos.

Como desafio, tenho a pretensão que o atual projeto possa inspirar outras experiências com atividades investigativas, envolvendo ações sociais dentro de práticas inovadoras, encontrando maneiras para desenvolver propostas de trabalho com atividades exploratórias. Trazendo para educação novas propostas para o ensino de matemática, oferecendo condições para que sejam estabelecidas maiores conexões entre a disciplina e o sujeito.

Portanto, todas essas discussões aqui apresentadas podem ser um passo inicial para futuras propostas de ensino, abrindo debates no campo da educação matemática com relação à importância de trazer métodos investigativos para o cotidiano das aulas, pois, com este projeto verificou-se o quanto é relevante a utilização de recursos que ofereçam uma metodologia diferenciada, e que procure estimular a prática de atividades que estabeleça um contexto de ação e interação, proporcionando uma maior compreensão e interesse pelas descobertas.

\section{Referências}

D’AMBRÓSIO, Ubiratan. Etnomatemática - Elo entre as tradições e a modernidade. Ed. Autêntica, Belo Horizonte, MG, 2005.

FREIRE, Paulo. Pedagogia da Autonomia - Saberes Necessários a Prática Educativa.

Ed. Paz e Terra. Coleção Leitura Edição Especial. Santa Efigenia, SP- 2007.

MORIN, Edgar. A Cabeça bem-feita-Repensar a Reforma Reformar o Pensamento. 14 ${ }^{\mathrm{a}}$ Edição -Ed. Bertrand Brasil, Rio de Janeiro, RJ -2008.

FERREIRA, A. C. Metacognição e desenvolvimento profissional de professores de Matemática: uma experiência de trabalho colaborativo. Tese (Doutorado em Educação) - Universidade Estadual de Campinas, Campinas, 2003.

GARCIA, D. E. S. Metodologia de projetos: vivências, resolução de problemas e colaboração na experiência educativa. Dissertação (Mestrado em Educação) Faculdade de Educação, Universidade Federal de Pelotas, Pelotas, 2006. 
PASSOS, L. F. O projeto pedagógico e as práticas diferenciadas: o sentido da troca e da colaboração. In:ANDRÉ, M. (Org.). Pedagogia das diferenças na sala de aula. São Paulo: Papirus, 1999.

PESSOA, C. A. dos S. Interação social: uma análise do seu papel na superação de dificuldades de resolução de problemas aditivos. In: REUNIÃO ANUAL DA ANPED, 25., Caxambu, 2002. Anais... Caxambu, 2002. P. 1-15. CD-ROM.

\section{Biografia Resumida}

Gabriele Silva Carneiro Batista; Licenciatura Plena em Matemática; Mestra, Universidade Estadual do Sudoeste da Bahia (UESB), Campus de Jequié; Professora efetiva do Colégio da Polícia Militar Eraldo Tinoco (CPM), Campus de Vitória da Conquista Bahia.

e-mail: gabriele1977@hotmail.com 